\title{
Effects of the peroxisome proliferator-activated receptor (PPAR)- $\gamma$ agonist pioglitazone on renal and hormonal responses to salt in diabetic and hypertensive individuals
}

\author{
A. Zanchi • M. Maillard • F. R. Jornayvaz • \\ M. Vinciguerra $\cdot$ P. Deleaval $\cdot$ J. Nussberger $\cdot$ \\ M. Burnier • A. Pechere-Bertschi
}

Received: 25 January 2010 /Accepted: 17 March 2010/Published online: 23 April 2010

(C) Springer-Verlag 2010

\begin{abstract}
Aims/hypothesis Glitazones are powerful insulin sensitisers prescribed for the treatment of type 2 diabetes. Their use is, however, associated with fluid retention and an increased risk of congestive heart failure. We previously demonstrated that pioglitazone increases proximal sodium reabsorption in healthy volunteers. This study examines the effects of pioglitazone on renal sodium handling in individuals prone to insulin resistance, i.e. those with diabetes and/or hypertension. Methods In this double-blind randomised placebo-controlled four-way crossover study, we examined the effects of pioglitazone (45 mg daily during 6 weeks) or placebo on renal, systemic and hormonal responses to changes in sodium
\end{abstract}

A. Zanchi $(\bowtie) \cdot$ M. Maillard $\cdot$ P. Deleaval $\cdot$ M. Burnier

Service of Nephrology, Department of Medicine,

Lausanne University Hospital,

Centre Hospitalier Universitaire Vaudois,

Lausanne, Switzerland

e-mail: azanchidel@hotmail.com

F. R. Jornayvaz $\cdot$ A. Pechere-Bertschi

Service of Endocrinology,

Diabetes and Nutrition and of Primary Care,

University Hospital of Geneva and University of Geneva,

Geneva, Switzerland

\section{Vinciguerra}

Department of Cell Physiology and Metabolism,

Faculty of Medicine, University of Geneva,

Geneva, Switzerland

\section{J. Nussberger}

Service of Vascular Medicine, Department of Medicine,

Lausanne University Hospital,

Centre Hospitalier Universitaire Vaudois,

Lausanne, Switzerland intake in 16 individuals, eight with type 2 diabetes and eight with hypertension.

Results Pioglitazone was associated with a rapid increase in body weight and an increase in diurnal proximal sodium reabsorption, without any change in renal haemodynamics or in the modulation of the renin-angiotensin aldosterone system to changes in salt intake. A compensatory increase in brain natriuretic peptide levels was observed. In spite of sodium retention, pioglitazone dissociated the bloodpressure response to salt and abolished salt sensitivity in salt-sensitive individuals.

Conclusions/interpretation Pioglitazone increases diurnal proximal sodium retention in diabetic and hypertensive individuals. These effects cause fluid retention and may contribute to the increased incidence of congestive heart failure with glitazones.

Trial registration: ClinicalTrial.gov NCT01090752

Funding: Hypertension Research Foundation Lausanne

Keywords Clearance - Glitazones · Hormones · Hypertension · Kidney Sodium · Type 2 diabetes
Abbreviations
ANP Atrial natriuretic factors
BNP Brain natriuretic protein
CHF Congestive heart failure
ERPF Effective renal plasma flow
FF Filtration fraction
HS High-sodium (diet)
LS Low-sodium (diet)
PAH Para-aminohippurate
PPAR Peroxisome proliferator-activated receptor
PRA Plasma renin activity 


\section{Introduction}

Glitazones are efficient oral hypoglycaemic agents with powerful insulin-sensitising properties that have sustained effects on blood sugar control [1]. A well known side effect is fluid retention exacerbated by insulin use. Peripheral oedema is seen in $5-15 \%$ of treated individuals. This side effect just about doubles the risk of congestive heart failure, but does not increase mortality [2]. There is no evidence that the increased risk of heart failure is due to a negative inotropic effect $[3,4]$, thus fluid retention remains the major contributor.

Based on these clinical observations, restriction of glitazones to individuals without congestive heart failure (CHF) New York Heart Association class III or IV has been recommended. The European Union has extended the recommendations to all individuals with New York Heart Association class I-IV CHF.

We have previously shown that glitazones increase renal sodium reabsorption in healthy volunteers [5]. Both direct and indirect effects of glitazones on renal sodium reabsorption have been proposed, through the direct activation of tubular peroxisome proliferator-activated receptor (PPAR)- $\gamma$ or indirectly through the activation of compensatory mechanisms secondary to the glitazone-induced vasodilation [6-8]. Experimental studies have shown that glitazones may increase sodium transport in the proximal convoluted tubules, the thick ascending limb and the collecting duct [9, 10].

The primary endpoint of this placebo-controlled, randomised, crossover study was to explore the effects of pioglitazone (45 $\mathrm{mg}$ once daily for 6 weeks) on the renal, hormonal and blood pressure responses to changes in sodium intake in a population prone to insulin resistance (i.e. hypertensive and/or type 2 diabetic individuals). Although many studies have been performed in animals, this is the first study to examine in hypertensive and/or type 2 diabetic individuals the renal sodium response to pioglitazone when exposed to a high- or a low-sodium diet.

\section{Methods}

Sixteen individuals were examined, eight with a diagnosis of type 2 diabetes and eight with a diagnosis of systemic hypertension. The participants were recruited by hospital placards detailing the study. Participants received a sum as compensation for travel and meal expenses. Exclusion criteria were any cardiac or renal diseases, anaemia and drugs such as aspirin, non-steroidal anti-inflammatory drugs and hormonal replacement therapy.

A full medical history was obtained and a complete physical examination was undertaken before inclusion. Type 2 diabetes was defined according to the American Diabetes Association criteria (fasting plasma glucose $\geq 7.0 \mathrm{mmol} / \mathrm{l}$ or casual plasma glucose $\geq 11.1 \mathrm{mmol} / 1$ in individuals without diabetic treatment). Among the eight individuals with diabetes, three were on a diet and five were treated with metformin that was maintained at the same dose throughout the study. Individuals receiving glitazone therapy or using insulin were excluded. Hypertension was defined as an office systolic blood pressure $\geq 140 \mathrm{mmHg}$ and/or a diastolic blood pressure $\geq 90 \mathrm{mmHg}$ in individuals not using blood-pressurelowering therapy. Among the diabetic individuals, three were taking either an angiotensin II receptor antagonist or an ACE inhibitor. Among hypertensive individuals, one was taking an ACE inhibitor. Blood-pressure-lowering therapy was discontinued for at least 2 weeks and individuals were included in the study if values did not exceed 160/100 mmHg. Premenopausal women were excluded, as were individuals with liver abnormalities or renal failure. The protocol was approved by the local hospital ethical committee in accordance with the principles of the Declaration of Helsinki as revised in 2000, and written informed consent was obtained from each individual.

\section{Procedure}

The study had a double-blind, randomised, placebocontrolled, twofold crossover design as shown in Fig. 1. A total of 64 ambulatory blood pressure measurement and hormonal and renal function studies were planned. Each individual was randomised to receive either pioglitazone $45 \mathrm{mg}$ once daily or (during the placebo phase) either placebo (if on diet alone before entering the study) or metformin (usual dose if on therapy before entering the study) for 6 weeks, with a 2 week wash-out period between the two treatment phases. Randomisation of the sequences of placebo and active treatment periods was performed by a doctor with no contact with participants and clinicians. Placebo and active treatment were prepared by a pharmacist, appeared indistinguishable and were dispensed in identical bottles.

From weeks 1 to 4 , individuals followed their usual diet. During weeks 5 and 6 of each treatment phase (placebo or pioglitazone), individuals received a low-sodium (LS) and a high-sodium (HS) diet for 1 week. The sequence of the diets was randomised, but each individual received the same sequence while receiving placebo or pioglitazone. The random allocation scheme was derived from a computer-generated list, which assigned diets according to a random sequence of numbers. Individuals were instructed to adjust their diet to reach a sodium intake of approximately $40 \mathrm{mmol} / 24 \mathrm{~h}$. The high-sodium diet was obtained by adding $6 \mathrm{~g}$ of sodium chloride to the individual's regular diet. On day 7 of each dietary period, $24 \mathrm{~h}$ ambulatory blood pressure was recorded, with measurements performed at $20 \mathrm{~min}$ intervals from 08:00 to 22:00 hours, and at 
Fig. 1 Detail of the 6 week study period, repeated twice: once with pioglitazone and once with placebo, with a 2 week wash-out period. The sequence of diets was randomised, but a given individual. ABPM, ambulatory blood pressure measurement; U24, 24 h urine each sequence was the same for collection

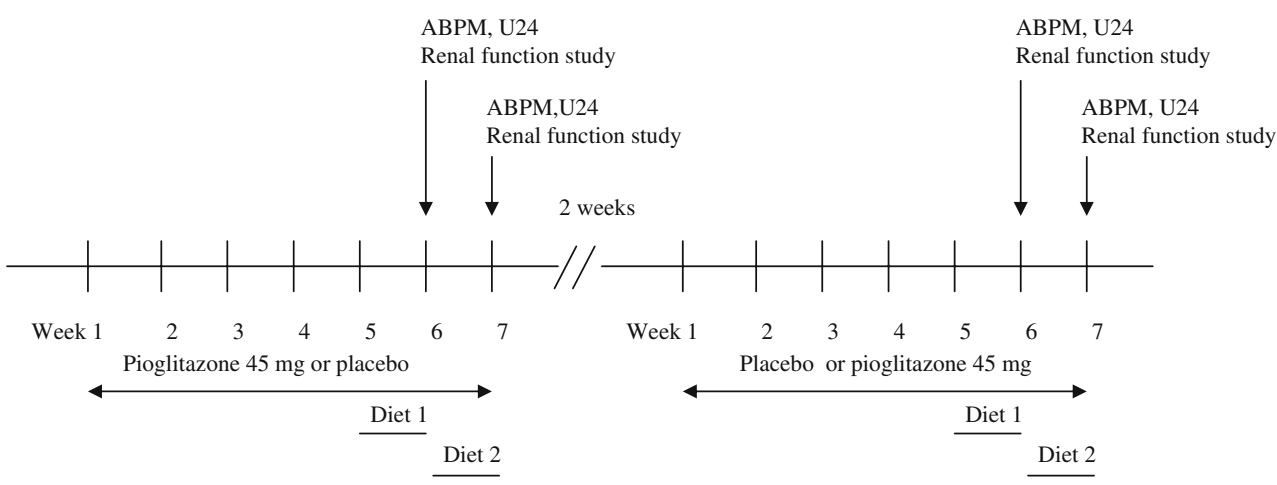

Endogenous trace lithium was measured by atomic absorption spectrophotometry as described previously [14]. Plasma renin activity [15, 16], plasma aldosterone [17] and atrial natriuretic peptide [18] were determined as described previously. BNP was measured by immunoassay (Biosite Triage BNP test, Biosite, Morges, Switzerland). Plasma insulin was determined by radioimmunoassay (Insulin-RIA, Pharmacia, Dübendorf, Switzerland).

Urinary electrolyte excretion rate was calculated as $U_{x} \times V$ ( $\mu \mathrm{mol} / \mathrm{min})$ and clearance $(\mathrm{ml} / \mathrm{min})$ calculated using the standard formula $C_{x}=U_{x} \times V / P_{x}$ where $U_{x}$ and $P_{x}$ are the urine and plasma concentrations of $x$ and $V$ is the urine flow rate in $\mathrm{ml} / \mathrm{min}$. into antecubital veins, one for the infusion of sinistrin (an analogue of inulin) and para-aminohippurate (PAH) and a second into the contralateral forearm for drawing blood. After an oral water load of $5 \mathrm{ml} / \mathrm{kg}$ and a 90 min equilibration period, two $1 \mathrm{~h}$ sinistrin and $\mathrm{PAH}$ clearances were obtained to measure glomerular filtration rate and effective renal plasma flow (ERPF). Blood was also drawn to measure serum electrolytes, including endogenous lithium, as well as plasma renin activity (PRA), plasma aldosterone, atrial natriuretic factors (ANP) and brain natriuretic peptide (BNP). Blood sampling for hormonal measurements was done supine after an hour of rest and before the water load. Leg volume was measured at the end of each phase and through a water immersion method.

\section{Analytical method and calculation of renal variables}

Insulin sensitivity indexes were assessed by HOMA-IR [13]. Urinary and plasma sodium and potassium were measured by flame photometry (IL-943, Instrumentation Laboratory, Milan, Italy) and creatinine by the picric acid method (Cobas-Mira, Roche, Basel, Switzerland). Serum and urinary uric acid was measured by the enzymatic method using an uricase-peroxidase chromogen sequence (AUPAP50, bioMérieux, Lyon, France, on a Cobas-Mira, Roche). Plasma and urinary sinistrin and PAH were determined by photometry (Autoanalyzer II-Technicon, Bran \& Luebbe, Norderstedt, Germany). Lithium clearance was used as a marker of renal proximal sodium clearance.

\section{Statistical analysis}

Data are expressed as mean \pm SEM. The statistical difference between the four different treatment periods (LS/placebo, HS/placebo, LS/pioglitazone, HS/pioglitazone) was evaluated for each variable by a one-way analysis of variance followed by the Fischer's comparison test. A level of $p<0.05$ was considered statistically significant. To examine the specific effects of pioglitazone in the same individual, the values obtained with placebo were subtracted from the values obtained with pioglitazone. The significance was examined by a one-sample $t$ test for a significant difference from 0 , with the zero value indicating no change; $p<0.05$ was considered statistically significant.

\section{Results}

Baseline characteristics of the individuals and tolerability profile

The baseline characteristics of individuals are shown in Table 1. There were no significant differences between the hypertensive and diabetic individuals. Among the hypertensive individuals, three had impaired fasting glucose and 
Table 1 Baseline characteristics of individuals

\begin{tabular}{llll}
\hline Characteristic & Diabetic $(n=8)$ & Hypertensive $(n=8)$ & All $(n=16)$ \\
\hline Age (years) & $56.8 \pm 3.2$ & $48.4 \pm 4.4$ & $52.5 \pm 2.8$ \\
Sex (female/male) & $4 / 4$ & $4 / 4$ & $8 / 8$ \\
Weight $(\mathrm{kg})$ & $77.0 \pm 6.5$ & $81.4 \pm 5.4$ & $79.2 \pm 4.1$ \\
BMI $\left(\mathrm{kg} / \mathrm{m}^{2}\right)$ & $27.7 \pm 1.9$ & $28.0 \pm 1.2$ & $27.9 \pm 1.1$ \\
Mean SBP $(\mathrm{mmHg})$ & $138.9 \pm 3.5$ & $150.5 \pm 4.8$ & $144.7 \pm 3.2$ \\
Mean DBP $(\mathrm{mmHg})$ & $84.3 \pm 3.7$ & $93.0 \pm 2.7$ & $88.7 \pm 2.5$ \\
Haematocrit $(\%)$ & $43.3 \pm 1.9$ & $43.2 \pm 1.6$ & $43.2 \pm 1.2$ \\
ALAT (U/l) & $46.4 \pm 9.2$ & $52.2 \pm 9.5$ & $49.3 \pm 6.2$ \\
Serum creatinine $(\mu \mathrm{mol} / \mathrm{l})$ & $78 \pm 5.6$ & $70 \pm 3.3$ & $74 \pm 3.3$ \\
OGTT & & & \\
Glycaemia $0^{\prime}(\mathrm{mmol} / \mathrm{l})$ & & $5.5 \pm 0.3$ & \\
Glycaemia $120^{\prime}(\mathrm{mmol} / \mathrm{l})$ & & $5.9 \pm 0.6$ & \\
\hline
\end{tabular}

ALAT, alanine transaminase; DBP, diastolic BP; SBP, systolic BP
Metabolic variables

No metabolic variable changed significantly during the study, although there was a clear trend towards a decrease in plasma insulin levels, HOMA-IR and uric acid levels during the pioglitazone phases (Table 2).

Weight and leg volume The average increase in weight with pioglitazone was of $1.1 \pm 0.5 \mathrm{~kg}$ on a low-sodium diet $(p=$

Table 2 Metabolic, hormonal and renal measurements

\begin{tabular}{|c|c|c|c|c|c|}
\hline \multirow[t]{2}{*}{ Variable } & \multicolumn{2}{|l|}{ Placebo } & \multicolumn{2}{|l|}{ Pioglitazone } & \multirow{2}{*}{$\begin{array}{l}\text { ANOVA } \\
p \text { value }\end{array}$} \\
\hline & LS & HS & LS & HS & \\
\hline \multicolumn{6}{|l|}{ Blood } \\
\hline Glucose $(\mathrm{mmol} / \mathrm{l})$ & $6.8 \pm 0.4$ & $6.3 \pm 0.3$ & $6.9 \pm 0.7$ & $6.9 \pm 0.7$ & NS \\
\hline Insulin (pmol/l) & $208.4 \pm 45.8$ & $168.1 \pm 23.6$ & $125.7 \pm 12.5$ & $127.1 \pm 14.6$ & NS \\
\hline HOMA-IR & $8.9 \pm 1.8$ & $6.3 \pm 0.9$ & $5.5 \pm 0.7$ & $5.4 \pm 0.8$ & NS \\
\hline ALAT (U/1) & $35 \pm 5.4$ & $32.8 \pm 5.5$ & $33.9 \pm 3.6$ & $32.1 \pm 5.0$ & NS \\
\hline Uric acid (mmol/l) & $378 \pm 21$ & $343 \pm 14$ & $346 \pm 23$ & $323 \pm 21$ & NS \\
\hline Protein $(g / l)$ & $72.8 \pm 0.9$ & $69.3 \pm 0.7^{\mathrm{a}}$ & $70.9 \pm 1.1$ & $68.7 \pm 0.9^{\mathrm{a}}$ & 0.01 \\
\hline PRA (ng ml ${ }^{-1} \mathrm{~h}^{-1}$ ) & $1.03 \pm 0.3$ & $0.37 \pm 0.13^{\mathrm{a}}$ & $0.86 \pm 0.2$ & $0.20 \pm 0.09^{\mathrm{a}}$ & 0.006 \\
\hline Aldosterone (pg/ml) & $119.6 \pm 18.7$ & $70.6 \pm 6.8^{\mathrm{a}}$ & $113.0 \pm 15.6$ & $66.5 \pm 6.0^{\mathrm{a}}$ & 0.006 \\
\hline ANP $(\mathrm{pg} / \mathrm{ml})$ & $25.8 \pm 5.1$ & $41.8 \pm 6.2$ & $26.6 \pm 5$ & $40.3 \pm 6.2$ & 0.085 \\
\hline $\mathrm{BNP}(\mathrm{pg} / \mathrm{ml})$ & $6.7 \pm 9.5$ & $12.8 \pm 4.9$ & $11.0 \pm 4.8$ & $17.3 \pm 5.3^{\mathrm{b}}$ & 0.4 \\
\hline \multicolumn{6}{|l|}{ Renal function studies } \\
\hline $\mathrm{UNa}(\mathrm{mmol} / 24 \mathrm{~h})$ & $59 \pm 16$ & $166 \pm 21^{\mathrm{a}}$ & $65 \pm 17$ & $163 \pm 20^{\mathrm{a}}$ & $<0.001$ \\
\hline Na clearance $(\mathrm{ml} / \mathrm{min})$ & $0.41 \pm 0.10$ & $1.05 \pm 0.10^{\mathrm{a}}$ & $0.35 \pm 0.07$ & $1.18 \pm 0.13^{\mathrm{a}}$ & $<0.001$ \\
\hline GFR $\left(\mathrm{ml} \mathrm{min} \min ^{-1}\left[1.73 \mathrm{~m}^{2}\right]^{-1}\right)$ & $68.0 \pm 4.4$ & $68.8 \pm 5.0$ & $62.4 \pm 5.0$ & $71.7 \pm 6.7$ & NS \\
\hline $\operatorname{ERPF}\left(\mathrm{ml} \mathrm{min}{ }^{-1}\left[1.73 \mathrm{~m}^{2}\right]^{-1}\right)$ & $397 \pm 34$ & $381 \pm 35$ & $354 \pm 41$ & $316 \pm 36$ & NS \\
\hline $\mathrm{FF}(\%)$ & $0.19 \pm 0.02$ & $0.20 \pm 0.02$ & $0.26 \pm 0.09$ & $0.36 \pm 0.14$ & NS \\
\hline
\end{tabular}

${ }^{a}$ HS diet vs LS diet on same drug

${ }^{\mathrm{b}}$ Pioglitazone vs placebo on same salt diet

ALAT, alanine transaminase; ERPF, effective renal plasma flow; UNa, 24 h urinary $\mathrm{Na}$ excretion 

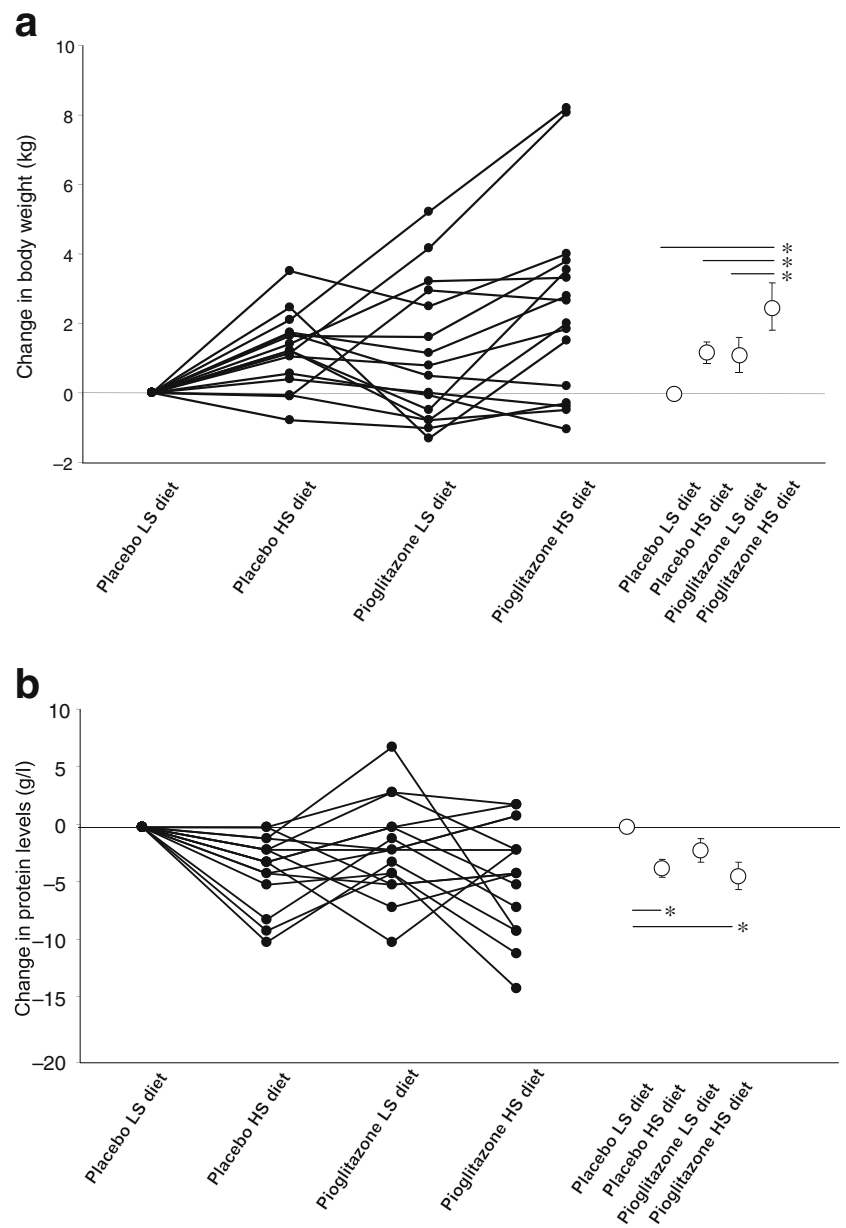

Fig. 2 a Individual changes and mean changes ( \pm SEM) in body weight $(\mathrm{kg})$ with weight at placebo/low-sodium-diet phase considered as baseline: $p=0.003$ by one way analysis of variance between phases. ${ }^{*} p<0.05$ by Fischer's comparison test between phases. b Individual changes and mean $( \pm$ SEM) changes in plasma protein level $(\mathrm{g} / \mathrm{l})$ with level of placebo/low-sodium-diet phase considered as baseline: $p=$ 0.006 by one way analysis of variance between phases. ${ }^{*} p<0.05$ by Fischer's comparison test between phases. Individual changes, black circles; mean changes, white circles

0.04 vs 0$)$ and of $1.3 \pm 0.6 \mathrm{~kg}(p=0.05)$ on a high-sodium diet. The increase in weight induced by pioglitazone was not significantly amplified by a high-sodium diet $(p=0.6)$. In comparison with the low-sodium diet, the high-sodium diet induced a weight gain of $1.57 \pm 0.31 \mathrm{~kg}(p=0.0002)$ during the placebo phase and of $1.84 \pm 0.56 \mathrm{~kg}$ during the pioglitazone phase $(p=0.005)$; the differences were not significant between pioglitazone and placebo. When the weight with the placebo low-sodium-diet phase was considered as a baseline, the increase in weight was comparable during the high-sodium placebo phase and the low-sodium pioglitazone phase and was highest during the high-sodium pioglitazone phase (Fig. 2a). Changes in protein levels were inversely correlated with changes in body weight ( $y=0.992-0.184 x, p=0.01)$ (Fig. 2b). Changes in leg volume were slightly but not significantly bigger when switching from a low-sodium to a high-sodium diet during the pioglitazone phase (control phase vs pioglitazone phase, $0.3 \pm 0.1 \%$ vs $0.5 \pm 0.4 \%$ ).

Hormonal measurements The high-sodium diet was associated with a decrease in PRA and aldosterone levels and an increase in ANP and BNP levels (Table 2). The diet-induced changes, however, reached significant levels only with PRA, aldosterone, ANP and BNP in diabetic individuals. In particular, changes in BNP levels were more pronounced in diabetic individuals: the mean \pm SEM for LS/placebo, HS/placebo, LS/pioglitazone and $\mathrm{HS} /$ pioglitazone phases were, respectively, $5.8 \pm 2.3$, $12.1 \pm 3.0,6.2 \pm 1.7,15.7 \pm 2.9 \mathrm{pg} / \mathrm{ml}(p=0.03)$. When examining the pioglitazone-induced hormonal changes, the only significant effect was the changes in BNP level during a high-sodium diet. Figure 3 depicts the individual pioglitazone-induced change in BNP levels; average changes were significantly higher with the high-sodium diet. The pioglitazone-induced changes in BNP levels were not significantly different during the high- and low-sodium-diet phases.

Renal function studies Urinary sodium excretion (mmol/ day) was higher on a high- vs a low-sodium diet during placebo and pioglitazone phases (Table 2). Lithium clearances $(\mathrm{ml} / \mathrm{min})$ increased also with the high-sodium diet during the placebo phase but not during the pioglitazone phase. Overall lithium clearances were significantly lower during the pioglitazone phase than during the placebo phase $(p=0.03)$. The average diurnal and nocturnal lithium clearance rates during different phases are shown in

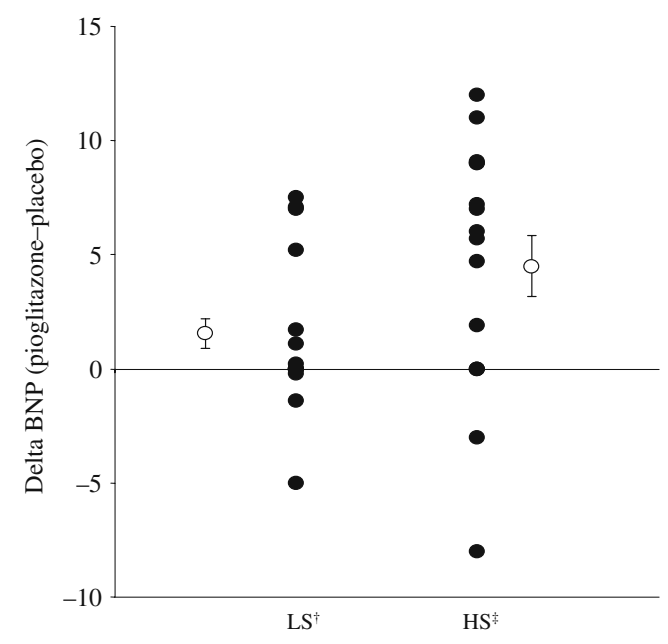

Fig. 3 Pioglitazone-induced individual and mean $( \pm$ SEM) changes in BNP levels from values obtained with placebo on the low-sodium or high-sodium diet: ${ }^{\dagger} p=0.1,{ }^{\ddagger} p=0.006$ for changes from low-sodium and high-sodium diets, respectively 


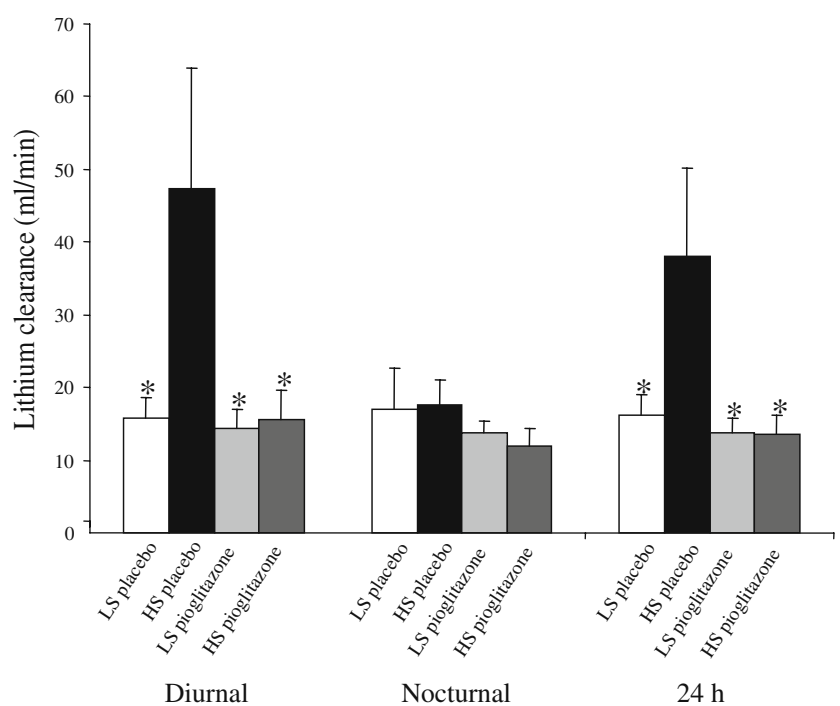

Fig. 4 Average lithium clearances (mean \pm SEM) during different phases: diurnal, nocturnal and 24 h. ${ }^{*} p<0.05$ vs high-sodium/placebo

Fig. 4. The increase in lithium clearance in response to the increase in sodium intake was observed exclusively during the day. This effect was abolished with pioglitazone. Changes in GFR, ERBF and filtration fraction (FF) were not significant during both diets and during the placebo and pioglitazone phases (Table 2).

Ambulatory blood pressure measurements Ambulatory blood pressure measurements are shown in Table 3. The high-sodium diet increased blood pressure slightly but not significantly. Pioglitazone did not have a significant effect on blood pressure control. The weight gain induced by a highsodium diet was not correlated with the blood pressure response to salt. Salt sensitivity was defined as an increase in mean $24 \mathrm{~h}$ ambulatory blood pressure on a high-sodium diet of $>5 \mathrm{mmHg}$. Of all individuals examined, three diabetic individuals and one hypertensive individuals fulfilled the criteria for salt sensitivity. On the high-sodium diet, $24 \mathrm{~h}$ mean blood pressure increased by a range of $6-17 \mathrm{mmHg}$ in these salt-sensitive individuals. In these individuals, pioglitazone treatment abolished the blood pressure response to salt (Fig. 5). The pioglitazone induced changes in BP response to salt were significantly different in salt-sensitive and saltresistant individuals $(p=0.04)$. In other words, the salt-

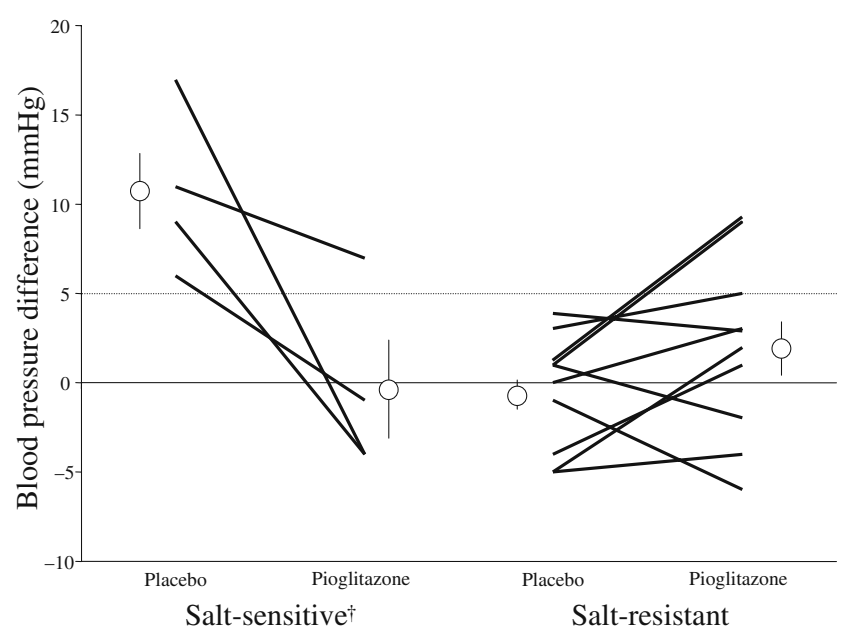

Fig. 5 Individual and mean $( \pm$ SEM) changes in $24 \mathrm{~h}$ mean ambulatory blood pressure measurements from a low-sodium diet to a high-sodium diet in salt-sensitive and salt-resistant individuals during the placebo and pioglitazone phases. ${ }^{\dagger} p=0.02$ for difference in salt-sensitive individuals and NS for salt-resistant individuals

sensitive individuals became salt resistant with pioglitazone treatment.

\section{Discussion}

Glitazones are powerful insulin sensitisers which are associated with sodium retention and an increased risk of congestive heart failure. This study was designed to examine the renal, hormonal and blood pressure response in diabetic and/or hypertensive individuals when exposed to a 1 week low- or high-sodium diet after 6 weeks of pioglitazone, $45 \mathrm{mg}$, in comparison with placebo.

This study demonstrates that pioglitazone treatment is associated with a rapid increase in body weight, due to sodium retention. Pioglitazone increases diurnal proximal sodium reabsorption without changing the renal haemodynamics or altering the modulation of the renin-angiotensin aldosterone system to changes in salt intake. These results suggest an effect of pioglitazone, either direct or indirect, on renal sodium handling. Compensatory mechanisms were observed, as demonstrated by the increase in natriuretic BNP levels with pioglitazone. These compensatory mechanisms may have prevented a drastic increase in body
Table 3 Blood pressure ambulatory measurements in different treatment groups

Data shown are mean systolic $\mathrm{BP} \pm \mathrm{SEM} /$ mean diastolic $\mathrm{BP} \pm \mathrm{SEM}$

\begin{tabular}{llllll}
\hline Variable & \multicolumn{2}{l}{ Placebo } & & \multicolumn{2}{l}{ Pioglitazone } \\
\cline { 2 - 3 } \cline { 5 - 6 } & LS & HS & & LS & HS \\
\hline $24 \mathrm{~h}$ & $128 \pm 5 / 80 \pm 2$ & $134 \pm 5 / 81 \pm 3$ & & $129 \pm 5 / 79 \pm 2$ & $133 \pm 4 / 80 \pm 2$ \\
Diurnal & $131 \pm 5 / 82 \pm 2$ & $138 \pm 6 / 84 \pm 3$ & & $135 \pm 5 / 83 \pm 2$ & $138 \pm 4 / 83 \pm 2$ \\
Nocturnal & $115 \pm 5 / 72 \pm 3$ & $118 \pm 4 / 72 \pm 2$ & & $114 \pm 5 / 70 \pm 2$ & $116 \pm 4 / 71 \pm 2$ \\
\hline
\end{tabular}


weight when exposed to a high-sodium diet. This study also demonstrates that, in spite of sodium retention, pioglitazone dissociates the blood pressure response to salt and abolishes salt sensitivity in salt-sensitive individuals.

Glitazones can influence body composition in different ways. Long-term studies show an increase in body fat in favour of a subcutaneous distribution [19-22]. In contrast, shorter-term studies demonstrate that the rapid increase in body weight is chiefly due to fluid retention. One 12 week study demonstrated that $75 \%$ of the increase in body weight was due to water [23]. In our study, 6 weeks of pioglitazone treatment was associated with changes in plasma protein levels that mirrored the changes in body weight, suggesting that fluid retention accounted for most of the increase in body weight during the pioglitazone phase.

The mechanisms of fluid retention due to glitazone therapy have been examined in experimental studies. Shortterm animal studies also show that there is a rapid increase in body weight during the first week of treatment, clearly due to an increase in water content $[6,7]$ and an increase in the epithelial sodium channel $(\mathrm{ENaC})$ activity. These effects were inhibited by amiloride, an $\mathrm{ENaC}$ inhibitor, and abolished in mice with specific deletion of the collecting duct PPAR- $\gamma$ suggesting an important role of glitazoneinduced sodium retention through $\mathrm{ENaC}$. These studies were welcomed with enthusiasm, as a specific treatment targeting $\mathrm{ENaC}$ is available in clinical practice (amiloride, spironolactone). However, clinical experience was not as successful as hoped with spironolactone, even though one clinical study showed superiority of spironolactone compared with furosemide for glitazone-induced fluid retention [8]. Recently, another experimental study cast some doubt on the effects of glitazones on $\mathrm{ENaC}$. In this study, the collecting duct gene inactivation of $\alpha-\mathrm{ENaC}$ did not prevent the rosiglitazone-induced fluid retention and neither rosiglitazone nor pioglitazone increased the activity of basal or insulin-stimulated $\mathrm{ENaC}$ in native collecting duct cells [24]. The contradictory results illustrate the complexity of glitazone-induced sodium reabsorption. Although rapid activation of renal sodium transporters may occur, compensatory or escape mechanisms may take place with time [25], either through the downregulation of sodium transporters or through the increase in natriuretic peptides. The inability to activate the compensatory mechanisms or concurrent treatment with insulin may alter these compensatory mechanisms and enhance fluid retention.

Changes in body weight during the 1 week sodium challenges were exclusively due to fluid shifts. Endogenous lithium clearances show that the kidney was unable to modulate proximal sodium reabsorption during the pioglitazone phase. However, compensatory mechanisms attenuated this effect with the consequent increase in body weight of only $270 \mathrm{~g}$ during the pioglitazone phase from the placebo phase when switching from a low-sodium to a high-sodium diet.

We have previously shown in an experimental study that, in spite of significant weight gain and water retention, glitazones dissociate the blood pressure response to salt and decrease the blood pressure response to angiotensin II [26]. Human studies show that treatment with rosiglitazone or pioglitazone is either neutral or associated with a mild decrease in blood pressure [27]. This study confirms for the first time that a sodium load during 1 week does not significantly change the blood pressure response in spite of increased sodium retention at the proximal level. These findings suggest that with pioglitazone, there are enough compensatory mechanisms - through vasodilation or increased release of natriuretic peptides - to compensate for the fluid retention and keep blood pressure low. Interestingly, a subset of salt-sensitive individuals became salt resistant during the pioglitazone phase. The relevance of these findings now needs to be confirmed in a larger study.

In contrast to our previous study in healthy volunteers, there was no increase in renin levels with pioglitazone [5]. This difference may be due to the fact that pioglitazone induced less vasodilation in our participants, because of endothelial dysfunction, than in healthy volunteers.

Some limitations of the study need to be addressed. The sample size may seem small but the crossover design of the study increased the statistical power. The goal was to explore the mechanisms of sodium retention with glitazones. Each of 16 individuals was examined four times with complete renal function studies, hormonal and $24 \mathrm{~h}$ blood measurements, and each served as their own control. This would not be possible in a population study. If a casecontrol study had been performed, a much higher number of individuals would have been needed to show a difference between cases and control because of the inter-individual variability of renal and hormonal measurements. Adherence to sodium intake was not monitored, but the significant hormonal and renal changes gave an indirect validation to good observance.

In conclusion, this study shows that pioglitazone increases proximal tubular sodium retention after 6 weeks, independent from a change in renal haemodynamics, and is counteracted by the release of BNP. Whether the glitazoneinduced increase in congestive heart failure is linked to sustained proximal sodium reabsorption and decreased compensatory release of natriuretic factors needs to be examined in population studies.

Acknowledgements We kindly thank O. Bonny (Service of Nephrology, Department of Medicine, Lausanne University Hospital, Centre Hospitalier Universitaire Vaudois, Lausanne, Switzerland) for his critical reading of the manuscript and suggestions and G. Wagner for her huge help with clinical procedures. 
Duality of interest The authors declare that there is no duality of interest associated with this manuscript

\section{References}

1. Kahn SE, Haffner SM, Heise MA et al (2006) Glycemic durability of rosiglitazone, metformin, or glyburide monotherapy. N Engl J Med 355:2427-2443

2. Lago RM, Singh PP, Nesto RW (2007) Congestive heart failure and cardiovascular death in patients with prediabetes and type 2 diabetes given thiazolidinediones: a meta-analysis of randomised clinical trials. Lancet 370:1129-1136

3. Erdmann E, Wilcox RG (2008) Weighing up the cardiovascular benefits of thiazolidinedione therapy: the impact of increased risk of heart failure. Eur Heart J 29:12-20

4. Dargie HJ, Hildebrandt PR, Riegger GA et al (2007) A randomized, placebo-controlled trial assessing the effects of rosiglitazone on echocardiographic function and cardiac status in type 2 diabetic patients with New York Heart Association Functional Class I or II Heart Failure. J Am Coll Cardiol 49:1696-1704

5. Zanchi A, Chiolero A, Maillard M, Nussberger J, Brunner HR, Burnier M (2004) Effects of the peroxisomal proliferator-activated receptor-gamma agonist pioglitazone on renal and hormonal responses to salt in healthy men. J Clin Endocrinol Metab 89:1140-1145

6. Guan Y, Hao C, Cha DR et al (2005) Thiazolidinediones expand body fluid volume through PPARgamma stimulation of ENaCmediated renal salt absorption. Nat Med 11:861-866

7. Zhang H, Zhang A, Kohan DE, Nelson RD, Gonzalez FJ, Yang T (2005) Collecting duct-specific deletion of peroxisome proliferator-activated receptor gamma blocks thiazolidinedioneinduced fluid retention. Proc Natl Acad Sci USA 102:9406-9411

8. Karalliedde J, Buckingham R, Starkie M, Lorand D, Stewart M, Viberti $G$ (2006) Effect of various diuretic treatments on rosiglitazoneinduced fluid retention. J Am Soc Nephrol 17:3482-3490

9. Yang T, Soodvilai S (2008) Renal and vascular mechanisms of thiazolidinedione-induced fluid retention. PPAR Res 2008:943614

10. Saad S, Agapiou DJ, Chen XM, Stevens V, Pollock CA (2009) The role of Sgk-1 in the upregulation of transport proteins by PPAR-\{gamma $\}$ agonists in human proximal tubule cells. Nephrol Dial Transplant 24:1130-1141

11. Gosse P, Ansoborlo P, Jullien VV, Lemetayer P, Clementy J (1997) Ambulatory blood pressure and left ventricular hypertrophy. Blood Press Monit 2:70-74

12. Burnier M, Rutschmann B, Nussberger J et al (1993) Saltdependent renal effects of an angiotensin II antagonist in healthy subjects. Hypertension 22:339-347

13. Mather K, Hunt A, Steinberg H et al (2001) Repeatability characteristics of simple indices of insulin resistance: implica- tions for research applications. J Clin Endocrinol Metab 86:5457-5464

14. Magnin JL, Decosterd LA, Centeno C, Burnier M, Diezi J, Biollaz J (1996) Determination of trace lithium in biological fluids using graphite furnace atomic absorption spectrophotometry: variability of urine matrices circumvented by cation exchange solid phase extraction. Pharm Acta Helv 71:237-246

15. Nussberger J, Fasanella d'Amore T, Porchet M et al (1987) Repeated administration of the converting enzyme inhibitor cilazapril to normal volunteers. J Cardiovasc Pharmacol 9:39-44

16. Poulsen K, Jorgensen J (1974) An easy radioimmunological microassay of renin activity, concentration and substrate in human and animal plasma and tissues based on angiotensin I trapping by antibody. J Clin Endocrinol Metab 39:816-825

17. Nussberger J, Waeber B, Brunner HR, Burris JF, Vetter W (1984) Highly sensitive microassay for aldosterone in unextracted plasma: comparison with two other methods. J Lab Clin Med 104:789-796

18. Nussberger J, Mooser V, Maridor G, Juillerat L, Waeber B, Brunner H (1990) Caffeine-induced diuresis and atrial natriuretic peptides. J Cardiovasc Pharmacol 15:685-691

19. Miyazaki Y, Mahankali A, Matsuda M et al (2002) Effect of pioglitazone on abdominal fat distribution and insulin sensitivity in type 2 diabetic patients. J Clin Endocrinol Metab 87:2784-2791

20. Kim SK, Hur KY, Kim HJ et al (2007) The increase in abdominal subcutaneous fat depot is an independent factor to determine the glycemic control after rosiglitazone treatment. Eur J Endocrinol 157:167-174

21. Hwang YC, Lee EY, Lee WJ et al (2008) Effects of rosiglitazone on body fat distribution and insulin sensitivity in Korean type 2 diabetes mellitus patients. Metabolism 57:479-487

22. Smith SR, de Jonge L, Volaufova J, Li Y, Xie H, Bray GA (2005) Effect of pioglitazone on body composition and energy expenditure: a randomized controlled trial. Metabolism 54:24-32

23. Basu A, Jensen MD, McCann F, Mukhopadhyay D, Joyner MJ, Rizza RA (2006) Effects of pioglitazone vs glipizide on body fat distribution, body water content, and hemodynamics in type 2 diabetes. Diabetes Care 29:510-514

24. Vallon V, Hummler E, Rieg T et al (2009) Thiazolidinedioneinduced fluid retention is independent of collecting duct alphaE$\mathrm{NaC}$ activity. J Am Soc Nephrol 20:721-729

25. Tiwari S, Blasi ER, Heyen JR, McHarg AD, Ecelbarger CM (2008) Time course of AQP-2 and ENaC regulation in the kidney in response to PPAR agonists associated with marked edema in rats. Pharmacol Res 57:383-392

26. Zanchi A, Perregaux C, Maillard M, Cefai D, Nussberger J, Burnier M (2006) The PPARgamma agonist pioglitazone modifies the vascular sodium-angiotensin II relationship in insulin-resistant rats. Am J Physiol Endocrinol Metab 291:E1228-E1234

27. Sarafidis PA, Nilsson PM (2006) The effects of thiazolidinediones on blood pressure levels - a systematic review. Blood Press 15:135-150 